\title{
¿Me dibujas un sentimiento?: un acercamiento a la enseñanza de los verbos de afección a través de la imagen metalingüística
}

\author{
MARÍA JosÉ Domínguez HervÁs \\ Hispania, escuela de español \\ maria.j.dominguez@hispania-valencia.com \\ RITA RODRÍGUEZ VARELA \\ Hispania, escuela de español \\ rita.varela@hispania-valencia.com
}

Resumen: No son pocas las ocasiones en las que, como docentes, nos enfrentamos a las dificultades de los estudiantes de español a la hora de adquirir, asimilar y utilizar los verbos de afección psicológica. La falta de comprensión del sentido tanto de la estructura sintáctica como de los aspectos semánticos y sociolingüístico de dichas construcciones pueden ser el origen de este bache en el proceso de aprendizaje.

Nos proponemos, siguiendo las recomendaciones del Marco Común Europeo de Referencia y los principios de la Gramática Cognitiva, contribuir al conjunto de experiencias docentes que ya han trabajado el uso de la imagen metalingüística para explicar contenidos gramaticales complejos. En este artículo, reflexionamos sobre una secuencia didáctica que utiliza ilustraciones como base del análisis y la descripción gramatical de las construcciones utilizadas para expresar sentimientos en español.

Palabras clave: imagen metalingüística, verbos de afección, Gramática Cognitiva.

\section{Could you draw a feeling for me?: An approach to verbs of psicological affection through metalinguistic images}

Abstract: This paper explores one of the challenges teachers of Spanish as an L2 often encounter: students' difficulties to understand, learn and use verbs of psychological affection. From our perspective, the lack of understanding of both syntactic and semantic logics as well as some socio-linguistic aspects involving these structures may be at the base of the difficulties of the learning process.

Following the recommendations of the Common European Framework of Reference and the principles of Cognitive Grammar, we intend to contribute to the set of teaching experiences that have already worked on the use of the metalinguistic image to explain complex grammatical content. In this article, we reflect on a didactic sequence that uses illustrations as a tool of analysis and grammatical description of structures used for express feelings in Spanish.

Key words: metalinguistic image, verbs of psychological affection, Cognitive Grammar 


\section{Introducción}

MJ: Me encanta tener la posibilidad de compartir nuestra experiencia con vosotros. Me encanta que os hayáis interesado por nuestra propuesta. Me encanta que estéis aquí incluso cuando son las 6’30 de un sábado. Vaya, que me encantáis. Rita, tú también me encantas.

R: Sí, yo también me encanto.

Con este pequeño diálogo inauguramos la presentación de nuestra propuesta didáctica en la última edición de Foro ELE en la Universitat de València. Pretendíamos poner en evidencia - de una manera más o menos cómica- una serie de estructuras que cualquier hispanohablante sería capaz de producir sin ningún esfuerzo. El uso del verbo encantar, como gustar y todas esas formas que relacionamos con la expresión de emociones o sentimientos está completamente integrado como parte de nuestra lengua madre. Sin embargo, no podemos decir lo mismo de los estudiantes de español como LE con los que trabajamos. Día a día los vemos dudar y cometer errores a la hora de utilizar unas estructuras que han sido denominadas de diferentes maneras; son los llamados verbos tipo gustar, verbos de sentimiento, verbos de corazón, verbos de afección psicológica. La cantidad de propuestas didácticas que existen sobre el tema es inabarcable ya que es un contenido esencial, presente en todos los niveles del currículo de ELE. Sin embargo, la realidad es que, incluso los aprendientes experimentados siguen cometiendo errores y tienen dudas al respecto de estas estructuras. En una primera aproximación al campo de estudio, detectamos errores fosilizados relacionados con cuatro aspectos:

a. el olvido constante de la preposición a (*iVosotros os molestan los mosquitos?)

b. la utilización imprecisa de pronombres (*Yo me odio las personas falsas)

c. la falta de concordancia entre el sujeto y el verbo (*Los españoles encantan comer paella)

d. la confusión entre las oraciones sustantivas de afección y las oraciones adverbiales de tiempo (*Me sorprende cuando me regalen flores)

Estos errores sugieren que los estudiantes no comprenden el significado de cada estructura, señalada implícitamente en cada uno de los elementos que conforman una determinada construcción. Es decir, cada preposición, cada pronombre, cada conector da cuenta de ese significado. Es más, la forma en la que se combinan esos elementos también es clave para la comprensión de la estructura.

Elaboramos, así una propuesta didáctica orientada a presentar cada elemento de las estructuras de afección psicológica como significativo. De esta manera subrayamos como necesaria la correlación sintáctica entre las partes de cada oración. Nuestro objetivo es el de proponer una metodología eficaz que ayude a subsanar los errores en el output de los estudiantes sin necesidad de profundizar en los fundamentos de la sintaxis. Huyendo de la visión de la gramática como un ente objetivo basado en la adquisición mecánica de reglas, la utilización de la imagen metalingüística (Romo, 2014, 2015, 2016) como herramienta para enfocar la didáctica desde la Gramática Cognitiva resultó ser una herramienta óptima para llevar a cabo nuestra idea. La utilización de la imagen para ilustrar las explicaciones gramaticales permite a los aprendientes visualizar el significado relacionado con cada forma y con una determinada conceptualización, esto es, con la visión del mundo que cada hablante busca expresar. 
A lo largo de este artículo, expondremos la experiencia didáctica que realizamos con varios grupos de estudiantes de español de diferentes niveles. En primer lugar, abordaremos el marco teórico que nos permitió sentar las bases de nuestro estudio. Concretamente, haremos una breve revisión de cómo se suele enfocar la enseñanza de los verbos de afección y nos centraremos en el enfoque de la gramática cognitiva, así como en la forma de emplear la imagen en la enseñanza y las posibilidades que nos abre el uso de la imagen metalingüística. En segundo lugar, presentaremos los diferentes pasos que dimos en nuestra propuesta didáctica, los cuales nacieron, como ya hemos anunciado, de los errores detectados en nuestros alumnos y de la necesidad de un enfoque sintáctico.

Finalmente, concluiremos valorando los resultados obtenidos y reflexionando sobre la necesidad de adoptar un nuevo método didáctico que permita a los alumnos comprender las diferentes posibilidades que nos aporta cada estructura gramatical para facilitarles la producción.

\section{Marco teórico}

\subsection{Otros enfoques sobre la didáctica de las estructuras de afección.}

El verbo gustar, como verbo modelo presente en las estructuras de afección, supone un reto tanto para los estudiantes de español como LE como para los docentes de este material. La confusión a la hora de abordar los verbos de afección psicológica nace del hecho de que tanto su semántica como la correlación establecida con los demás elementos de las estructuras en las que se insertan no resultan claras para los aprendientes.

Diversos estudios han analizado esta problemática y una buena parte de los trabajos orientados a la didáctica del verbo gustar se ha centrado en encontrar estructuras equivalentes en las lenguas de origen. Los estudiantes que parten del inglés como L1 o idioma de referencia suelen encontrarse con un problema morfosintáctico al relacionar el verbo gustar con el inglés to like (Whitley, 2002 en Catoira, 2008; Cerezo, Caras y Leow, 2016). Gustar es un verbo intransitivo que rige complemento indirecto -la persona que experimenta el sentimiento- mientras que to like es un verbo transitivo -en el que el sujeto es la persona que siente una emoción- (Catoira, 2008; Cerezo, Caras y Leow, 2016). A esto se le añade que en las estructuras de afección psicológica el sujeto aparece pospuesto. Esta mecánica contribuye a la confusión del estudiante cuando compara la lógica sintáctica de estos verbos con su equivalente en inglés (Catoira, 2008; Mayoral Hernández, 2012).

Belinger (1961: 134) hace referencia a un pequeño «truco» de los enseñantes de español para angloparlantes que consiste en reemplazar el verbo gustar por el inglés to please con el objetivo de paliar la confusión del sujeto con el objeto (Chocolate pleases me). No obstante, esa solución le parece «insatisfactoria» por razones de orden morfosintáctico y propone utilizar el verbo to appeal a la hora de explicar la estructura del verbo gustar (Chocolate appeals to me). Briscoe, Bull y LaMadrid (1974 cit. en Catoira, 2008) proponen por su parte trabajar en torno a to disgust (disgustar) y relacionarla con la forma agramatical to gust en calidad de antónimo. Algunos manuales dirigidos al público angloparlante (Van Patten et al., 2008: 60, cit. en Catoira, 2008) optan por trabajar desde la construcción to be pleasing. Sin embargo, todas estas 
soluciones inducen a los estudiantes a identificar erróneamente el régimen dativo del verbo gustar como una estructura transitiva y no siempre solucionan el problema de la estructura inversa.

Otras investigaciones, por su parte, proponen focalizar sobre otros aspectos a la hora de abordar la didáctica de las estructuras de gustar. Así, Briscoe (1989) advierte sobre la necesidad de trabajar, primero, la conjugación en presente de los verbos de la primera conjugación y, después, los pronombres de objeto indirecto antes de comenzar con la expresión de gustos y aficiones. Catoira (2008: 3) añade que familiarizar a los estudiantes tanto con la preposición $a$ como con «la dinámica estructural arbitraria del español en cuanto al orden de los elementos en la frase», sería también necesario para facilitar, llegado el momento, la asimilación de los verbos de afección. Complementariamente, apuntan tanto Catoira (2008) como Mumin (2010), convendría reforzar con la semántica y la pragmática la práctica gramatical de los verbos como gustar.

\subsection{La perspectiva cognitiva}

A finales de los años setenta comienzan a surgir algunos estudios que enfocan la lingüística desde un punto de vista cognitivo, tomando gran relevancia una década después gracias a las aportaciones de Langacker (1990) y Lakoff (1993). Se trata de una corriente que considera que la lengua es el resultado de la cognición humana por lo que no es posible entenderla, enseñarla o aprenderla si no se tiene en cuenta este factor como punto de inicio. En este sentido, rechaza la visión de la lengua como un ente autónomo y busca estudiar el significado de las formas, pues existe una relación ineludible entre la forma -unidad lingüística del lenguaje-, el significado -estructura semántica de una unidad simbólica- y su conceptualización - modo en que el significado se procesa cognitivamente- (Cadierno y Lund, 2004: 139-140).

La Gramática Cognitiva tiene en consideración el hecho de que la lengua no puede escapar a la visión del hablante, pues es este el que elige una determinada forma y no otra a la hora de expresar un mensaje. Por este motivo, estudia la lengua centrándose en la intención comunicativa del hablante y en su selección de determinadas formas para construir significados. Por otro lado, como señala Ruiz Campillo (2007: 1) la Gramática Cognitiva retoma la relación existente entre significado y significante expresada por Saussure, así explica que es «una reivindicación de la indisolubilidad de "forma" y "significado": la nueva unidad básica no es la forma en sí misma, no es el significado en sí mismo, sino una unidad simbólica en la que forma y significado (significado conceptual) son inseparables». Seguidamente, señala cuáles son los pasos que un docente debe seguir para convertirse en un «profesor cognitivo»: el primer «movimiento de conciencia» iría del objetivismo al experiencialismo, aceptando que la lengua no es objetiva y por tanto cualquier regla que se pretenda fijar vendrá acompañada de una gran cantidad de excepciones, «la lengua "representa" la realidad tal y como el sujeto la percibe y quiere que la perciba el oyente» (2007: 2); con el segundo movimiento se trataría de pasar del estudio de la forma al estudio del significado con el que el hablante las emplea; finalmente, el tercer movimiento de conciencia, debe ir de la norma al uso, dejando de lado una gramática basada en reglas que obvian las manifestaciones lingüísticas en su totalidad, es decir, también los usos incorrectos o considerados 
«periféricos» deben ser tenidos en cuenta, pues la gramática vive «en la mente de las comunidades que la usan, y cuando el uso real va en contra del libro de gramática, no es la realidad la que falla: es el libro que no es capaz de dar cuenta de ella» (2007: 2). El gran aporte del cognitivismo es considerar la perspectiva del hablante expresada en la selección de formas. Por esta razón, no se puede pretender una explicación objetiva de cada estructura gramatical. En esta línea, Castañeda (2004: 1) indica que «muchas estructuras lingüísticas se distinguen más por ofrecer una configuración representacional distinta de una misma situación concebida que por corresponder a diferencias factuales o reducibles a condiciones de verdad».

El concepto de prototipo es esencial dentro de esta corriente lingüística. Entendemos, desde Lakoff (1993), que podemos correlacionar elementos con muy pocas características en común gracias a las asociaciones mentales que permiten la metáfora y la metonimia, así como la polisemia. De esta manera la Gramática Cognitiva establece que cada elemento que conforma el lenguaje puede ser relacionado con su significado esencial que explicaría su función en todas las construcciones en las que aparece.

\subsection{Imagen y pedagogía}

La imagen ocupa un lugar central dentro del contexto actual en el que desempeñamos nuestro trabajo como docentes. Los códigos verbales y visuales componen a la par nuestros mensajes y los elementos icónicos sirven de apoyo a lo verbal y en ocasiones incluso lo sustituyen (López García, 2005 en Romo 2016).

No obstante, la relación entre la imagen y la pedagogía no es algo reciente. Aunque se pueda hablar del uso didáctico de las imágenes ya en el periodo paleolítico, de acuerdo con Romo Simón (2014: 4) «el origen "oficial" de los materiales visuales como soporte al aprendizaje se remonta al s.XVII, cuando Comenius decidió incluir ilustraciones en sus libros de educación básica». Actualmente es prácticamente imposible imaginar la práctica docente sin la ayuda de los soportes visuales.

La imagen es omnipresente en el aula, tanto presencial como online, y las clases de ELE no son una excepción. De hecho, el Marco Común Europeo de Referencia (2001) alienta a utilizar la imagen en la enseñanza de lenguas ya que los beneficios que aporta esta alianza son múltiples. Sánchez (2009: 2-5) alega que, convenientemente adaptada al nivel y edad de los aprendientes, la imagen no solo facilita la explicación de la gramática y el léxico, sino que sirve de apoyo memorístico y transmite contenidos culturales de manera más directa. Además, sirve como elemento dinamizador de la motivación, enriquece la metodología y estimula el intercambio de ideas y experiencias.

Todo depende de la manera y el objetivo de utilizar estos elementos. Romo Simón (2014) asegura que los manuales de español como lengua extranjera hacen un uso intensivo de la imagen con el fin de servir de soporte y apoyo al texto verbal y de hacer su material más atractivos para el mercado. Sin embargo, según Goldstein (2012: 20), todavía los libros más actuales de ELE dirigen el foco de atención a los textos escritos mientras que las imágenes cumplen un papel secundario. Es el momento, afirma Romo Simón (2014) de reforzar el rol de las imágenes dentro de la enseñanza de lenguas. En un contexto tan fuertemente marcado por la imagen como el actual, la imagen puede comenzar a «definir también la gramática» (2014: 19) y no limitarse a «ejemplificarla» (2014: 13). 
La Gramática Cognitiva, por su parte, concibe los apoyos visuales como una herramienta esencial a la hora de analizar y describir la gramática; se trata, en palabras de Llopis-García (2017), de convertirse en el "profesor Pictionary» y poner los elementos visuales al servicio de la ilustración de «las representaciones mentales de las formas lingüísticas».

\subsubsection{La imagen metalingüística}

Como docentes, cada vez que utilizamos las tradicionales líneas del tiempo o las escalas para localizar los adverbios de frecuencia, estamos haciendo uso de lo que Romo Simón (2014: 14) denomina imagen metalingüística. Adaptar esa práctica cognitiva supone crear un código «extraordinariamente simple y limitado» que sirva a los docentes «para ilustrar y definir fenómenos gramaticales».

Desde un enfoque cognitivista, si aceptamos la existencia de prototipos en el lenguaje entendiéndolos como significados esenciales de los elementos lingüísticos- sería conveniente apoyar la reflexión gramatical sobre una serie de imágenes esquemáticas que permitan explicar el sentido y la función de cada elemento dentro de las diferentes estructuras gramaticales (Gálvez, 3 de diciembre de 2019). Nuestra mente traduce a imágenes la lengua por lo que podemos hacer el proceso inverso, traducir los elementos de la lengua a imágenes sencillas para poder establecer relaciones entre conceptos gramaticales complejos. Es más,

Gran parte de la lengua es la traducción de imágenes que están en nuestra mente. Como profesores de idiomas tenemos que evocar imágenes en la mente de nuestros estudiantes, pues sin ellas no puede haber un aprendizaje de idiomas satisfactorio (Goodey, 1997, cit. en Arnold, 2000: 287).

En los últimos tiempos, se han venido publicando algunas experiencias didácticas que, dentro del terreno de ELE, han explorado las posibilidades de esta herramienta. Este mismo autor propone la utilización de esta herramienta a la hora de trabajar los contrastes pretérito imperfecto/pretérito indefinido o ser/estar. Igualmente, la práctica presentada por Gálvez (21 de diciembre de 2019) también se centra en esta última problemática. Otras inspiradoras propuestas son las de Isabel Leal (14 de octubre 2019; 21 de diciembre de 2019; 23 de diciembre de 2019) y sus ejemplos sobre los determinantes y pronombres definidos e indefinidos o el uso de las preposiciones. García Ortega y Prunyonosa (2019) por su parte, presenta una aproximación a las estructuras de probabilidad.

En el terreno editorial, por el contrario, la presencia de la imagen metalingüística, así como de otras herramientas conectadas con la gramática cognitiva, es anecdótica en los manuales de ELE (Romo, 2014). Es llamativo, sin embargo, que muchos de los autores que se interesan por este aspecto arguyen en que sería beneficioso crear materiales en esta línea (Ruiz Campillo, 2007: 9) y, subsiguientemente, investigar sobre las consecuencias de este enfoque en los procesos de enseñanza-aprendizaje de una lengua extranjera. La presente propuesta se orienta hacia ese propósito. 


\section{Propuesta didáctica reflexiva}

\subsection{Encuesta inicial}

Tal y como hemos afirmado más arriba, intuimos que la confusión y consecuente fosilización de errores en lo referente a las estructuras de afección se debe a la carencia de análisis sintáctico. Los estudiantes no son conscientes de la lógica que correlaciona los elementos de las oraciones. Para asegurarnos de que nuestro presupuesto era cierto, decidimos pasar un pequeño cuestionario a un grupo de 8 estudiantes de diferentes orígenes que habían llegado al nivel C. A estos usuarios experimentados se les supone un dominio de la LE, así como la capacidad de reflexionar fácilmente a nivel sintáctico. A través de 6 preguntas de respuesta abierta, invitábamos a los estudiantes a reflexionar sobre

a. la diferencia entre oraciones con estructuras dativas (Me gusta el chocolate) y transitivas (Quiero chocolate),

b. el valor de la preposición a en las construcciones dativas,

c. el uso de los pronombres en ambos tipos de oraciones,

d. sobre si su dominio de dichas construcciones se debe a la comprensión de su mecánica o a la memorización de estructuras fijas,

e. las dificultades que han encontrado a lo largo de su proceso de adquisición de la lengua al respecto de los verbos de afección y sobre la persistencia de sus dudas.

Confirmamos que, a pesar de que utilizan diferentes estructuras con fluidez y relativa corrección, repiten siempre las mismas fórmulas y existe una gran confusión a la hora de explicar cuál es la función de cada elemento.

Teniendo en cuenta las respuestas de los estudiantes pusimos en práctica la secuencia didáctica que exponemos a continuación, con la cual intentamos poner en valor el significado esencial de cada elemento, así como su sentido dentro del conjunto de las estructuras de afección.

\subsection{La preposición $a$}

Presente en el español desde sus orígenes, la preposición $a$ es una de las palabras más polivalentes de nuestra lengua. Ya en latín, su antecesora ad servía para expresar todos los valores de la actual $a$, además de otros que actualmente cumplen otras preposiciones, como hasta (Morera, 1988).

Los estudiantes de ELE aprenden a familiarizarse con la preposición $a$ desde los niveles iniciales, la utilizan con más o menos atino a la hora de producir textos orales y escritos, y no muestran especial dificultad a la hora de entender su significado prototípico; la dirección de la acción desde el sujeto. Durante la secuencia didáctica que presentamos aquí, invitamos a los estudiantes a pensar en estructuras gramaticales que contuvieran la preposición $a$. Los usos relacionados con la dirección, el destinatario, la hora exacta aparecieron rápidamente en los niveles más básicos. Los estudiantes de nivel intermedio también reconocieron la presencia de la preposición en perífrasis incoativas del tipo 
empezar/comenzar/ponerse $+a+$ infinitivo. Incluso se llegó a mencionar su uso en el ámbito culinario con la expresión carne a la brasa. Resulta especialmente llamativo, sin embargo, que los estudiantes no mencionaran la partícula $a$ en relación con el verbo gustar ni con cualquiera de los verbos que expresan el sentimiento que nos provoca algo. Tal y como afirma Ruiz Campillo (14 de noviembre de 2007), los estudiantes son completamente capaces de hacerse entender omitiendo la preposición en esta estructura. Según el autor, ignorar o añadir $a$ no supone producir «variaciones de la estructura formal ampliamente redundantes, es decir, de baja capacidad de contraste entre significados». No obstante, la gramática cognitiva entiende que «no hay formas ni estructuras sintácticas totalmente redundantes», por lo que «siempre hay un espacio para hacer que el alumno tome conciencia del valor de la forma que malinterpreta o ignora» (Ruiz Campillo, 2007).

Así, propusimos a nuestros estudiantes que encontraran un dibujo con el que sustituir la partícula $a$ en los ejemplos que habían mencionado. Se trataba de explorar, a través del «pensamiento metafórico» (Llopis-García, 2015: 51) la semántica de preposición $a$. En otras palabras, de reflexionar junto a los estudiantes sobre el significado operativo central de esta preposición y plasmar gráficamente su prototipo.

Conformar una representación gráfica de $a$-un pequeño elemento que en este tipo de construcciones pasa desapercibido- nos ha ayudado a enfocar de una manera muy concreta la gramática. Se trata de entender cada uno de los elementos presentes en la oración como una unidad simbólica que se correlacionan el resto de partes de las construcciones gramaticales. Las construcciones sintácticas no sin, sin embargo, una mera «suma de los significado de las partes, sino que parte del significado depende de la construcción sintáctica seleccionada por el hablante» (Gras, Santiago y Polanco, 2004).

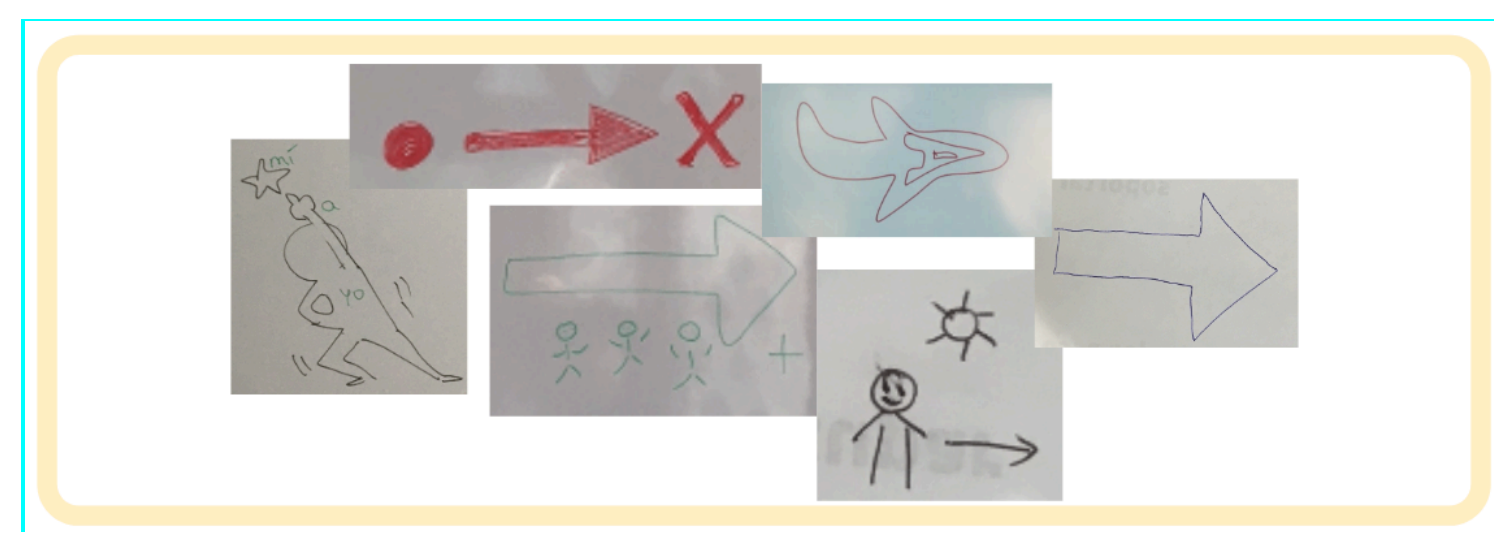

Imagen 1. Representación de la preposición a

Obtuvimos resultados muy similares. Como puede observarse, los estudiantes conceptualizan la preposición $a$ como un marcador de dirección, con el efecto de una acción, como un vector que conecta un origen y un destino. Resulta igualmente interesante comprobar cómo la mayoría de los estudiantes trazaban su dibujo de izquierda a derecha, identificando no tanto el sentido espacial sino la secuenciación temporal. La dirección del trazo nos envía a la metáfora conceptual «el tiempo es espacio» (Lakoff, 1993; Radden, 2002; Nuñez, 2003). Los hablantes, de acuerdo con numerosas investigaciones en Psicolingüística, representamos el tiempo a través de conceptualizaciones del espacio y esta relación queda plasmada en la lengua cuando hablamos del movimiento, la orientación, la distancia y la duración de una acción 
(Boroditsky, 2000, 2001; Boroditsky \& Ramscar, 2002; Nuñez \& Sweetser, 2006; Tversky, Kugelmass, \& Winter, 1991 cit. en Doquin de Saint-Preux y Masid, 2019).

Inferimos pues que, aunque los estudiantes parecían conceptualizar sin dificultad el significado prototípico de la preposición $a$, no eran capaces de identificar la función de

esta dentro de las construcciones de afección. Dicho de otro modo, el hecho de que no la vean significativa puede ser una de las razones por las que la olviden constantemente y caigan en errores del tipo *María le gusta leer o *Nosotros nos encanta ir a la playa (Ruiz Campillo, 2007). El siguiente paso debería ser entonces que los estudiantes comprendieran que la presencia de esta partícula articula la relación entre los demás elementos gramaticales de las estructuras de afección. Para ello fue necesario adentrarse en el uso de los pronombres.

\subsection{El significado de los pronombres}

Uno de los grandes obstáculos al que deben enfrentarse tanto docentes como aprendientes es el sistema de pronombres personales átonos de la lengua española. Como señalan Gras, Santiago y Polanco (2004), la problemática reside en que, por un lado, los estudiantes reciben explicaciones puramente sintácticas que no son capaces de entender por falta de conocimiento teóricos y, por otro lado, los manuales realizan presentaciones incompletas que impiden una visualización global del sistema de pronombres. Lo cierto es que la mayor parte de las explicaciones que se dan a los alumnos, tanto en los manuales como en las aulas, parten de la idea de que existen verbos tipo gustar y verbos tipo odiar que deben aprender de memoria, pero no se aporta una razón o una reflexión de la diferencia existente entre ambos.

La consecuencia de estos factores es que, llegados a un nivel superior, los alumnos afirmen cosas como que me gusta el chocolate es un gusto personal mientras que quiero o amo el chocolate es una respuesta a una pregunta o que me gusta es enfático y amo es una afirmación. Asimismo, preguntados sobre el papel concreto de los pronombres, las respuestas fueron que sustituían sustantivos o que eran enfáticos. Esto demuestra que nunca han comprendido la esencia de estos verbos y que, por tanto, los utilizan como autómatas y por eso muchas veces son ellos mismos los que no entienden por qué siguen cometiendo errores a pesar de su alto nivel.

Con el objetivo de suplir esta carencia provocada por la incomprensión, era necesario seguir utilizando la imagen metalingüística, esta vez para simbolizar el sujeto, en el caso de los verbos como amar, y los pronombres, en el caso de los verbos como gustar. No obstante, debía hacerse sin dejar de lado la preposición pues cada elemento de este tipo de oraciones sustantivas ocupa un lugar sintáctico clave. Situamos la preposición en un lugar central y atendiendo a su simbolización, les preguntamos a los alumnos dónde colocarían el pronombre personal y dónde los pronombres de complemento para encontrar la dirección de cada estructura. A continuación, les pedimos que crearan una imagen que los simbolizara y todos coincidieron en simplemente dibujar la silueta de una persona.

Gracias a este ejercicio, creamos una disposición fundamental para ellos, pues al situar la preposición en el centro con su simbolización pictórica marcando la dirección de cada elemento, obtuvimos una imagen mental de los dos tipos de estructuras. Nuestro interés por crear esta fotografía, se debe a que, como observa Castañeda Castro (2004) 
siguiendo a Lakoff y Johnson (1980), cuando construimos imágenes visuales, facilitamos la interpretación de conceptos y estructuras abstractas, pues estamos representándolas. Por otro lado, nuestro cerebro lee los textos como miles de pequeñas imágenes, pegadas unas a otras, por lo tanto, facilitamos su lectura, es decir, su comprensión. Pero, además, facilitamos su memorización pues, como demuestra la teoría del Picture Superiority Effect, el cerebro humano recuerda mejor las imágenes que las palabras, ya que «los conceptos más fácilmente recordables son los que pueden asociarse a objetos representables "imaginísticamente"» (Castañeda, 2004: 13).

\subsection{El verbo}

Estructuras gramaticalmente incorrectas como *Me echo de menos estar con mis amigas, *Quiero mucho las montañas de mi país o *Me gusta tú abundan en los textos de nuestros estudiantes de ELE en el nivel más básico y aparecen ocasionalmente en las producciones de nivel intermedio e incluso avanzado. Estos ejemplos ilustran la confusión de los aprendientes a la hora de identificar en qué casos la figura humana es el sujeto de la acción -origen del sentimiento- y cuándo simplemente experimenta una emoción provocada por algo o alguien.

Gras, Santiago y Polanco (2004: 423) reconocen que las estructuras con dativo -a las que se ajusta en buena parte de las ocasiones el verbo gustar - resultan «extrañas» para los no nativos. Para estos autores la dificultad reside, por una parte, en que

el argumento humano [en muchas de las estructuras construidas con verbo gustar] no es el sujeto, sino un dativo, mientras que el sujeto es un argumento no necesariamente humano $\mathrm{y}$, además, aparece pospuesto en lugar de preceder al verbo (2011: 423).

Es importante, afirman los autores, «llamar la atención sobre la no agentividad del dativo», esto es, el hecho de que el «argumento humano» es, en cierta medida, pasivo ya que simplemente experimenta el sentimiento, pero no es la causa de este (2004: 423). Sin embargo, el sujeto en estos casos, el elemento que causa el sentimiento experimentado por el dativo suele ser no humano.

Ahora bien, no podemos olvidar que es posible encontrar el mismo verbo en construcciones reflexivas y en construcciones de dativo (Me aburro de estar tanto tiempo en casa vs. Me aburre este silencio). Incluso, si en estructuras como No le cuentes tu vida a tu vecina, la vas a aburrir interpretamos que hay un sujeto agente que lleva a cabo la acción de aburrir, podemos afirmar que algunos verbos pueden presentarse también dentro de estructuras transitivas (2004: 423) y este polimorfismo supone una dificultad adicional para nuestros estudiantes.

Por último, los estudiantes deben, no solo interiorizar estas estructuras, sino que además deben «contrastarla con otras y elegir el pronombre adecuado en cada caso» (2004: 423). Resulta complicado para los estudiantes comprender que dos verbos como querer y gustar, por ejemplo, siendo tan similares en su significado, presenten construcciones diferentes (2004: 423).

A la hora de explicar la diferencia entre estos dos verbos, por ejemplo, muchos estudiantes eligen uno u otro en función de lo que ellos identifican como la intensidad del sentimiento (querer significa, para algunos, tener un sentimiento más fuerte que gustar), la consecuencia de esta emoción (si quiero algo, busco conseguirlo, pero si me 
gusta, simplemente siento esa emoción) o su temporalidad (quiero algo ahora, pero me gusta siempre).

Adentrarnos en la diferencia semántica o pragmática de las diferentes estructuras puede resultar enormemente farragoso como argumenta Zahir Mumin (2010) en su reflexión sobre la enseñanza de los verbos encantar, caer bien y gustar a estudiantes anglófonos. De acuerdo con su experiencia, se debe poner especial énfasis en «las estructuras sintácticas de gustar y otros verbos parecidos de manera explícita» con el objetivo de que los estudiantes comprendan que la correlación de los elementos está cargada de significado (Mumin, 2010: 305).

Así, decidimos trabajar diferentes estructuras en contraste evidenciando las diferencias entre las estructuras a través de la imagen metalingüística. Teniendo en cuenta la relación entre el sujeto y el complemento indirecto que habíamos trabajado en la actividad anterior, pedimos a los estudiantes que dibujaran las dos oraciones Me gusta el chocolate y Quiero chocolate dándoles una serie de elementos: una figura humana, una flecha y una caja donde podría caber cualquier cosa. En esta imagen mostramos algunos de los resultados que obtuvimos.
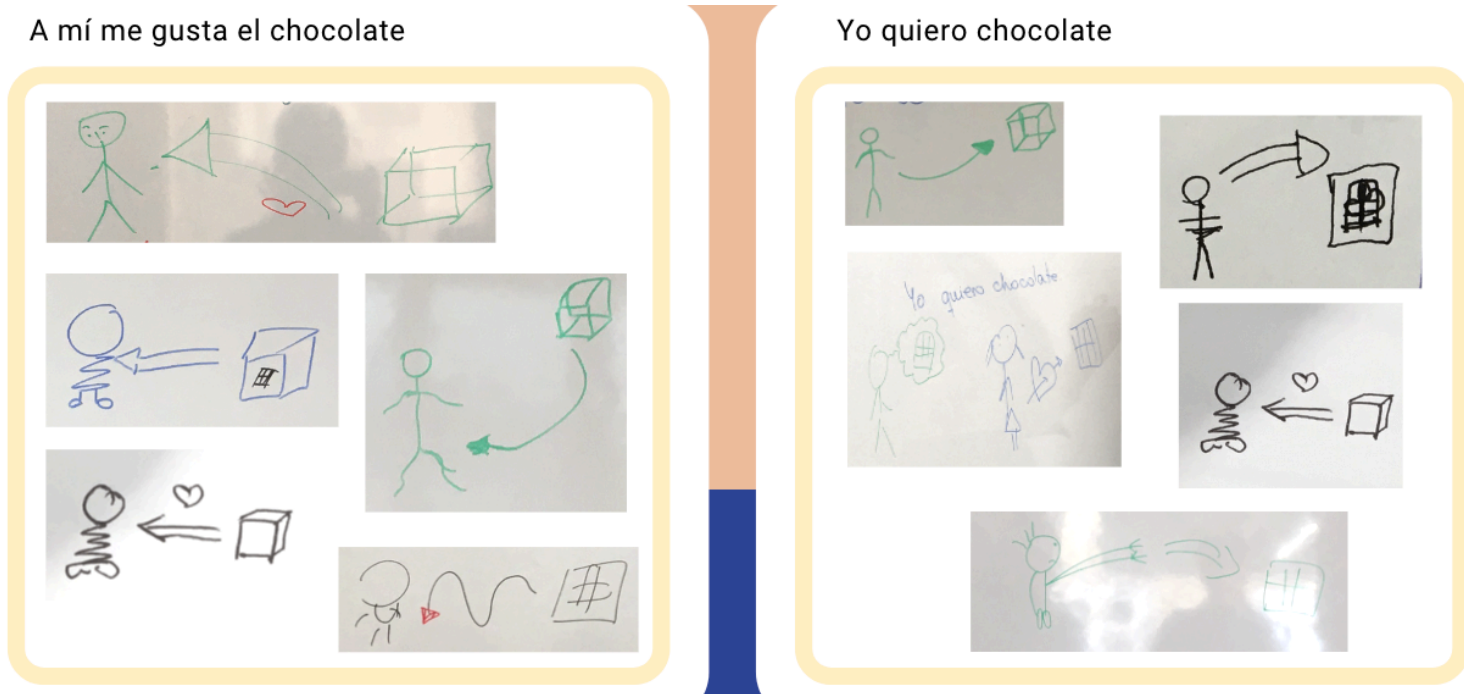

Imagen 2. Ilustraciones de la estructura dativa y la estructura transitiva

Fue sorprendente comprobar que incluso habiendo trabajado los conceptos anteriores algunos estudiantes no veían la diferencia entre ambas estructuras. Incluso en el nivel B2, donde los estudiantes se mostraban perfectamente capaces de producir estructuras con el verbo gustar, encantar o sorprender en relación a objetos y acciones, los dibujos reflejaban que la relación sintáctica entre elementos no se llegaba a comprender. Las imágenes correspondientes a yo quiero chocolate y me gusta el chocolate eran casi idénticas en un primer momento. Solo, una vez analizados los dibujos, los estudiantes fueron capaces de corregirse y de realizar satisfactoriamente la tarea sobre estructuras menos comunes como: me gustas, te quiero, me gusto o me odio. $\mathrm{Y}$ es que, en ese momento del proceso "abrimos la caja" para descubrir que en ella no solamente podemos encontrar objetos sino también personas, acciones y momentos. Entendimos que en las estructuras dativas lo que hay en la caja es el origen del sentimiento, esto es, la cosa que provoca la emoción que sentimos. 


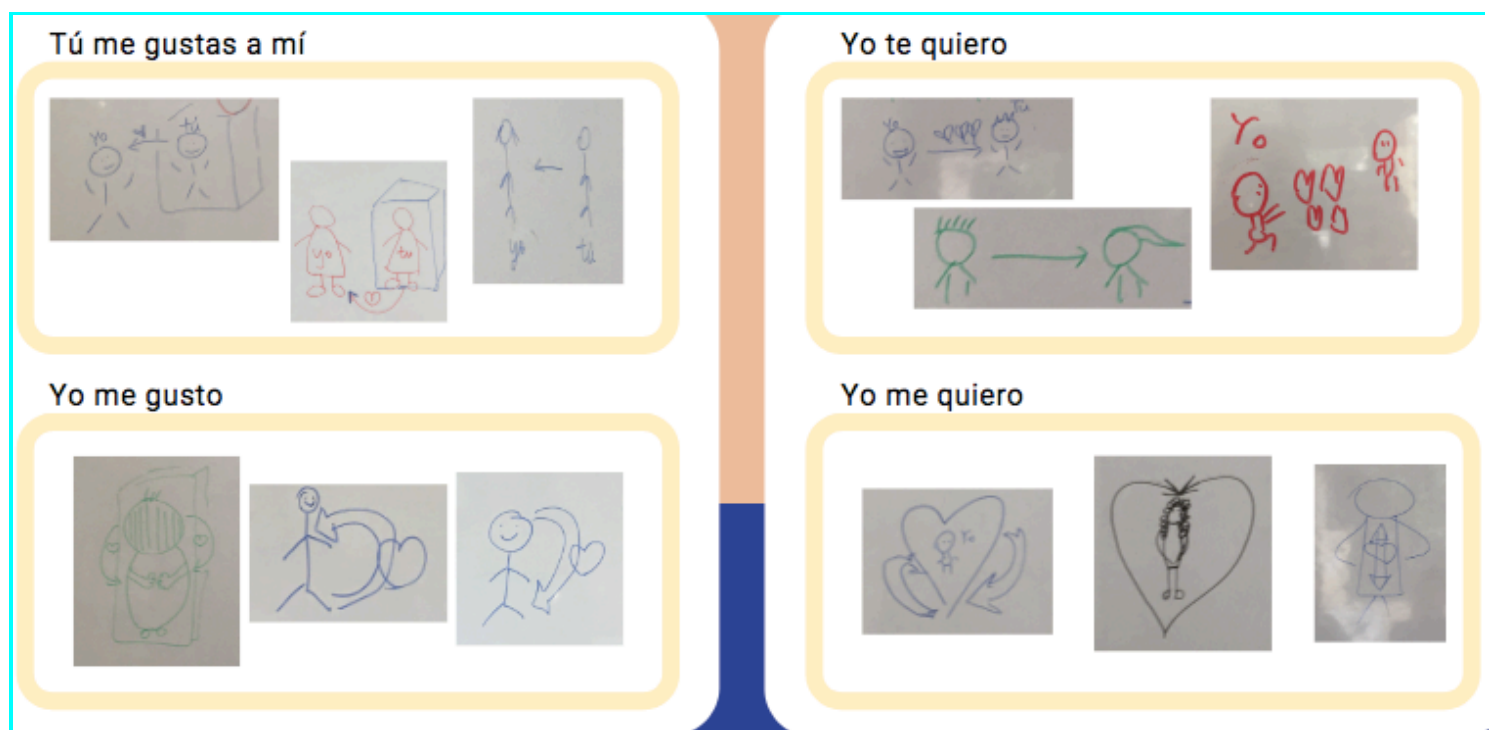

Imagen 3. Representación de las estructuras dativas y transitivas con sujeto y objeto de persona, y variaciones reflexivas.

Con esta actividad desmontamos lo que consideramos el gran mito en torno a los llamados verbos de sentimiento o afección. En una buena parte de los manuales y materiales con los que trabajamos los docentes de ELE, sobre todo con niveles básicos, el verbo gustar y otros que encontramos insertos en las estructuras dativas se trabajan como verbos defectivos. Repetimos, una y otra vez que estos verbos se conjugan en tercera persona, tanto singular como plural. No es hasta que el alumnado llega a un nivel intermedio-alto que se les presentan estructuras en la que los verbos aparecen conjugados en todas las personas. En este trabajo nos preguntamos: ¿Por qué ocultarles a nuestros estudiantes que los llamados verbos tipo gustar cuentan con todas sus formas tanto en el indicativo como en el subjuntivo? ¿Qué sucede cuando una secuencia didáctica sobre el verbo gustar en la que se ha presentado la morfología de manera incompleta se termina con la famosísima canción de Manu Chao "Me gustas tú"? Tal vez debamos centrarnos en la correlación de los elementos de las estructuras de afección y no incidir en la mera memorización y repetición de listados.

\subsection{Oraciones adverbiales de tiempo y oraciones sustantivas de afección}

La diferencia existente entre lo que se expresa y donde se pone el foco de atención al utilizar una oración sustantiva de afección y una oración adverbial de tiempo era otro punto que debíamos tratar en nuestro estudio. Como señalábamos en la introducción, entre los diferentes errores recopilados, observamos una frecuente confusión entre estos dos tipos de oraciones que derivaba en una mezcla de las diferentes estructuras gramaticales de cada una. Este error de selección tan común, se produce porque, en general, a los alumnos no se les suelen proporcionar los elementos necesarios para poder entender la lógica del lenguaje (Ruiz Campillo, 14 de noviembre de 2007) y, una vez más, nos valimos de la imagen metalingüística como elemento de reflexión y comprensión.

Pedimos a los alumnos que simbolizaran las oraciones yo me divierto cuando juego contigo y me gusta que me hables y, para profundizar todavía más en las posibilidades 
que nos ofrece la gramática, rescatamos el famoso «me gusta cuando callas» de Neruda, convirtiéndolo en me gusta cuando hablas, por ser más acorde con el deseo de cualquier profesor de lengua. Como ya habíamos elaborado la imagen metalingüística de los verbos de afección, nos centramos en crear diferentes dibujos que pudieran representar de manera significativa el momento en que ocurre una acción $\mathrm{y}$, tras varias ideas, llegamos juntos a la imagen de una nube. Disponiendo ahora de todos los elementos, pasamos a representar las tres frases, obteniendo los siguientes resultados:

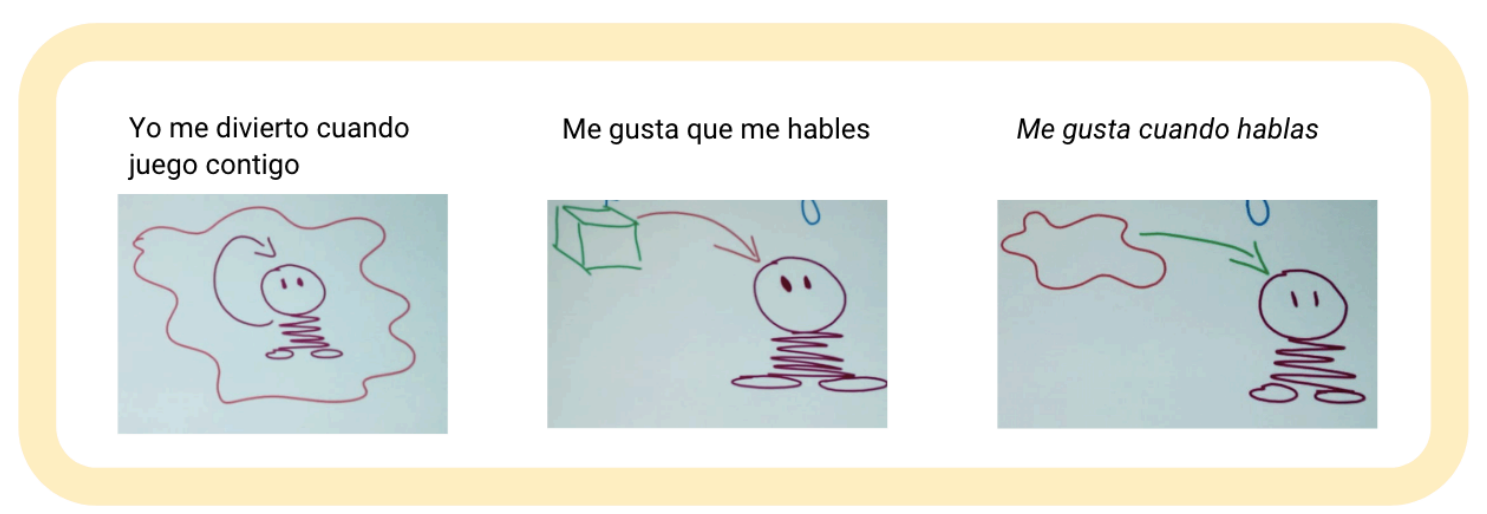

Imagen 4. Representación de oraciones adverbiales de tiempo y sustantiva de afección.

Como se puede observar, la imagen metalingüística aportó a los estudiantes esa lógica fundamental a la que aludíamos, es decir, les permitió ver la diferencia entre las oraciones sustantivas de afección, donde prima la emoción vivida por el experimentador y las oraciones adverbiales de tiempo, en las que el elemento relevante es el tiempo en el que una emoción o acción se produce. Se trata de un tipo de oraciones que representan un momento, al igual que lo hacen los adverbios, pero abren la posibilidad de especificar más detalladamente ese marco temporal. Y es, justamente, en esa especificación y en esa relación que se establece entre los eventos de la oración principal y la subordinada (Bosque y Demonte, 1999), donde encontramos la clave que nos permite comprender qué estructura debemos poner en uso. Con este último punto, pretendíamos que los estudiantes vieran claramente la diferencia entre me gusta que me digas la verdad, donde mi papel es el de experimentador y por tanto priorizo el sentimiento que algo me provoca y no importa cuándo, y yo soy feliz cuando hablo contigo, donde yo soy un sujeto que disfruta e interviene en un momento concreto, es decir, que me sitúo dentro de un determinado momento en el que siento una emoción. Por otro lado, cabe señalar que el uso del subjuntivo en las oraciones adverbiales de tiempo se produce cuando la oración subordinada tiene un carácter no asertivo, es decir, nos remite a situaciones que no hemos experimentado todavía, aspecto que marca una gran diferencia con el empleo del subjuntivo en las oraciones sustantivas.

\section{Reflexiones finales}

Como anunciábamos al inicio, con esta propuesta hemos pretendido ofrecer un enfoque metodológico alternativo sobre los verbos de afección, uno de los contenidos más problemáticos del español.

Nuestro objetivo principal no es tanto eliminar los errores para siempre, pues no se trata de una fórmula mágica, sino de hacer conscientes a los estudiantes de la necesidad de entender las oraciones como un conjunto de elementos significativos. Ha quedado 
demostrado que un método puramente comunicativo no es lo eficiente que se esperaba cuando se concibió, pero tampoco necesitamos gramatizar y guiar a los estudiantes hacia la memorización sistemática (Llopis-García, Real Espinosa y Ruiz Campillo, 2012; González y Cabot, 2015). Gracias al enfoque cognitivo y al uso de la imagen metalingüística, pudimos huir de la visión secular del lenguaje basada en pautas y automatismos, pudimos optar por una visión descriptiva basada en la comprensión de las diferentes posibilidades que nos ofrece la lengua para expresar la realidad. La lengua no es objetiva, es una representación subjetiva del mundo de cada hablante, en palabras de Campillo, «la lengua "representa" la realidad tal y como el sujeto la percibe y quiere que la perciba el oyente» (Ruiz Campillo, 2007: 2). Esta selección de las formas para expresar una determinada percepción es realizada de forma automática por el hablante nativo y, para situarlo a su nivel, el profesor de lengua extranjera debe dotar al aprendiente de los recursos necesarios para poder hacer ese cambio de enfoque de una misma realidad. A través de la reflexión, el estudiante podrá optar, en el caso de los diferentes tipos de oraciones que hemos estudiado, por situarse como un experimentador o como un sujeto pleno. Podrá priorizar la emoción que está experimentando o el momento en que dicha emoción se produce. En resumen, podrá entender cómo cada elemento de una oración juega un papel significativo en el significado final y, por lo tanto, podrá entender dónde está su error.

Por otro lado, cabe señalar, que este primer paso que hemos dado, nos permitirá seguir complejizando las estructuras al combinar los verbos de afección con estructuras condicionales, finales, causales o complementos de régimen verbal, entre otros, hasta conseguir que los hablantes extranjeros tengan un abanico de posibilidades de expresión más a la par con el de los hablantes nativos.

Otra cuestión muy importante es que al haber preparado un enfoque en el que no solo se da una lección sobre la sintaxis de los verbos de afección, sino que además en dicha reflexión participan los estudiantes, estamos llenándolos de autonomía y provocando que, a partir de este momento, empiecen a plantearse si los conceptos que no entienden de la gramática o que les resultan extraños, son el resultado del significado o de la función de alguno de sus componentes, lo que los llevará a mirarlos y analizarlos desde una nueva perspectiva.

Al fin y al cabo, esto tiene mucho que ver con el modelo de docente que queremos ser; aquel que pretende que sus estudiantes memoricen y utilicen algo que no comprenden o aquel que invita a sus alumnos a ser críticos y no aceptar que algo carece de sentido y simplemente hay que aprenderlo así. La lengua es algo muy bonito, pero también muy perfecto, pues estructura cada elemento de forma significativa de modo que cumpla su función primordial: ser la expresión de un pensamiento, de un momento, de una emoción, es decir, de cada partícula que conforma al ser humano. Como decía George Steiner «el habla constituye la sístole y la diástole del ser constante» (1973: 86), debemos pues transmitir lo mejor posible todo eso a nuestros queridos estudiantes.

\section{Bibliografía}

ARNOLD, J. (2000). La dimensión afectiva en el aprendizaje de idiomas. Madrid: Edinumen.

Bolinger, D. L. (1961). «Three Analogies», Hispania, 44 (1), pp. 134-137. 
BRISCOE, L. A. (1989). «Making Gustar Meaningful», Hispania, 72 (3), pp. 747-48.

CAdierno, T. y Lund, K. (2004). "Cognitive Linguistics and Second Language Acquisition: Motion Events». En Van Patten, B., Williams, J., Rott, S. \& Overstreet, M. (eds.), Form-Meaning Connections in Second Language Acquisition (pp. 139-144). Nueva Jersey: Lawrence Erlbaum.

Castañeda Castro, A. (2004). «Potencial pedagógico de la Gramática Cognitiva. Pautas para la elaboración de una gramática pedagógica de español/LE», Revista Electrónica de Didáctica/Español Lengua Extranjera, 0. Recuperado el 14/02/2020 de: https://www.educacionyfp.gob.es/dam/jcr:08b22007-7d71-4d54-877d7550f01287e6/2004-redele-0-06castaneda-pdf.pdf

CATOIRA, L. (2008). «La problemática del verbo gustar en los manuales universitarios de ELE», Tonos Digital: Revista de Estudios Filológicos, 16.

Cerezo, L., Caras, A., y Leow, R. P. (2016). «The effectiveness of guided induction versus deductive instruction on the development of complex Spanish gustar structures», Studies in Second Language Acquisition, 38(2), pp. 265-291.

Demonte, V. y BosQue, I. (1999): Gramática descriptiva de la lengua española. Madrid: Espasa.

Doquin de SAINT-Preux, A. y MASID, O. (2019). «Winter is coming. Representaciones cognitivas y lingüísticas en la conceptualización del tiempo». Trabajo no publicado presentado en II Seminario Nebrija-Difusión de lingüistica cognitiva y ELE: aportes de la investigación para la didáctica, Madrid.

GÁlveZ, V. (3/12/2019). «¿Por qué se dice ahora que dibujar la gramática es útil? [Mensaje en un post]». Un blog para profesores de español. Recuperado de https://formacionele.com/por-que-se-dice-ahora-que-dibujar-la-gramatica-es-util/

GÁlvez, V. (21/12/2019). "Quien dibuja la gramática, piensa dos veces». En Montmany y Sans (coord.). Encuentro Práctico de Barcelona 2019. Experiencia práctica no publicada presentada en Barcelona.

GoldsteIn, B. (2012). «El poder de la imagen. El uso de las imágenes en la clase de ELE», Mosaico, 29, pp. 19-23

GonZÁlez, M. y CABOT, M. (2015). «¡No gramatices! Por qué hay que analizar la lengua en el aula de español», en F. Herrera (ed.), La formación del profesorado de español. Cuadernos de didáctica (pp. 53-60). Barcelona: Difusión.

GARcía Ortega, Ó. y PrunYONOSA TOMÁs, M. (2018). Una aproximación a la selección de modo a través de la "imagen metalingüística" en los adverbios de duda. Madrid: UNED.

Gras Manzano, P., Santiago Barriendos, M. y Polanco Martínez, F. (2004). «Tienes que aprendértelos ya, que llevas tres años. Los pronombres personales átonos en la clase de E/LE. Un enfoque construccionista». En M. A. Castillo Carballo, O. Cruz Moya, y J. M. García Platero (coord.), Las gramáticas y los diccionarios del español como segunda lengua: deseo y realidad (pp. 419-426). Sevilla: ASELE.

LEAL, Isabel (2019). «¿Se puede dibujar la gramática?». En Montmany y Sans (Coord). Encuentro Práctico de Barcelona 2019. Taller no publicado presentado en Barcelona. 
LEAL, Isabel (14/10/2019). «Dibujar la gramática [Mensaje en un post]». Campamento norte. Recuperado de https://campamentonorte.com/dibujar-la-gramatica/

Llopis García, R., Real Espinosa, J. M., y Ruiz CAmpillo, J. P. (2012). Qué gramática aprender, qué gramática enseñar? Madrid: Edinumen.

Llopis GARCÍA, R. (2013). LdeLengua 70 con Reyes Llopis hablando de gramática [audio de podcast] Recuperado de: http://eledelengua.com/ldelengua70-con-reyesllopis-hablando-de-gramatica-2/

LLOPIS GARCÍA, R. (2015). «Las preposiciones y la metáfora del espacio: aportaciones y potencial de la lingüística cognitiva para su enseñanza», Journal of Spanish Language Teaching, 2(1), pp. 51-68.

LAKOFF, G. (1993). «The contemporary theory of metaphor». En A. Ortony (ed.), Metaphor and Thought (pp. 202-251). Cambridge: Cambridge University Press.

LANGACKER, R. W. (1990). Concept, image and symbol: the cognitive basis of grammar. Berlín: Mouton de Gruyter.

MECD (2002) [2001]. Marco común europeo de referencia para las lenguas: aprendizaje, enseñanza, evaluación. Madrid: Ministerio de Educación, Cultura y Deporte

MAYORAL HeRnÁNDEZ, R. (2012). «Teaching Subject Position in Spanish: Gustar Verbs, Unaccusatives and the Impersonal Passive», Journal of Language Teaching and Research, 3(2), pp. 321-330.

MorerA, M. (1988). Estructura semántica del sistema preposicional del español moderno. Fuerteventura: Cabildo Insular de Fuerteventura.

Mumin, Z. (2010). «La docencia de las estructuras sintácticas del verbo gustar: el presente y el pasado», Revista de Investigación Lingüistica, 13, pp. 299-310.

Romo Simón, F. (2014), «La gramática visual del español», MarcoELE Revista de Didáctica ELE, 19.

ROMO SIMÓN, F. (2015), «La imagen metalingüística de ser y estar», RESLA, 28 (1).

Romo Simón, F. (2016) «La imagen metalingüística como imagen pedagógica», RedELE, 28, pp. 1-28.

Ruiz CAmpillo, J. P. (2007). «Gramática congitiva y ELE», MarcoELE: Revista de Didáctica Español Lengua Extranjera, (5), 2.

SÁnCHEZ, G. (2009). «El uso de las imágenes en la clase de E/LE para el desarrollo de la expresión oral y escrita». MarcoELE, 8 .

STEINER, G. (1973). Extraterritorial. Ensayos sobre literatura y la revolución lingüística. Barcelona: Barral. 